\title{
Effects of deep cryogenic treatment on mechanical and tribological properties of AISI D3 tool steel
}

\author{
Nay Win KHUN ${ }^{1}$, Erjia LIU ${ }^{1, *}$, Adrian Wei Yee TAN ${ }^{1}$, D. SENTHILKUMAR ${ }^{2}$, Bensely ALBERT ${ }^{3}$, D. MOHAN LAL \\ ${ }^{1}$ School of Mechanical and Aerospace Engineering, Nanyang Technological University 50 Nanyang Avenue, Singapore 639798, Singapore \\ ${ }^{2}$ Department of Mechanical Engineering, P.A.College of Engineering and Technology, Pollachi 642002, TN, India \\ ${ }^{3}$ QuEST Global Services-NA, Inc., Greenville, SC 29615, USA \\ ${ }^{4}$ Department of Mechanical Engineering, College of Engineering, Guindy, Anna University Chennai 600025, India \\ Received: 14 June 2014 / Revised: 18 May 2015 / Accepted: 30 June 2015 \\ (C) The author(s) 2015. This article is published with open access at Springerlink.com
}

\begin{abstract}
In this study, the effects of deep cryogenic treatment (DCT) on the mechanical and tribological properties of AISI D3 tool steel were investigated together with a systematic correlation between their hardness and wear resistance. It was found that conventionally heat treated AISI D3 tool steel samples were significantly hardened via an additional DCT, which was attributed to the more retained austenite elimination, more homogenized carbide distribution and more reduction in carbide size in the samples. As a result, the hardened AISI D3 samples exhibited reductions in their friction and wear during rubbing against alumina and 100Cr6 steel balls under different normal loads due to the effectively hindered removal of surface materials. The results clearly showed that the DCT was an effective way to improve the mechanical and tribological properties of the AISI D3 tool steel samples as the tribological performance of the tool steel samples was significantly influenced by their hardness.
\end{abstract}

Keywords: AISI D3 tool steel; deep cryogenic treatment; hardness; friction; wear

\section{Introduction}

In a metal forming process, a tool can be exposed to extreme surface demanding conditions, where the mechanical and, especially, tribological properties of the tool are crucially important [1]. As wear is an important issue associated with industrial components, the cost of wear to industry is relatively high. Therefore, improved tool materials and processes to provide a solution for mitigating tribological losses are necessary for industrial applications.

Normally, a conventional heat treatment (CHT) of a tool steel can reduce retained austenite in the steel in order to extend the tool lifespan. However, transforming the retained austenite into martensite reduces the tool life via micro-cracking because the

*Corresponding author: Erjia LIU.

E-mail: MEJLiu@ntu.edu.sg transformed martensite is more brittle than the tempered martensite [2]. Deep cryogenic treatment (DCT) has been used in aerospace, automotive and electronic industries to improve the wear resistance of engineering materials by eliminating retained austenite to a greater extent [3]. A significant improvement in wear resistance of deep cryogenic treated tool steels is observed in tribological tests when compared to tool steels that are conventionally heat treated, quenched and tempered [4]. It was reported that the DCT was a promising treatment to improve the wear resistance of tool steels due to the elimination of retained austenite and precipitation of fine carbides and their uniform distribution [4-16]. Dixit et al. [17] reported an improvement in the wear resistance of D5 tool steel by DCT without properly correlating to the hardness. Dhokey et al. [18] studied the effect of tempering after DCT of D3 tool steel and found that decreases in hardness and wear resistance with multiple tempering of deep cryogenic 
treated D3 tool steel. Molinari et al. [19] reported that an execution of DCT on quenched and tempered high speed steel tools increased hardness and reduced tool consumption and downtime for the equipment set up. The DCT is a permanent treatment process that is supplement to a CHT process. However, it is still necessary to understand more about DCT process and its mechanisms and benefits in order to successfully add it to a regular heat treatment cycle for manufactured components [3].

In this study, three groups of AISI D3 tool steels, such as as-received, conventionally heat treated without tempering and deep cryogenically treated without tempering tool steel samples, were tested to study their mechanical and tribological properties. Optical microscope (OM), scanning electron microscope (SEM), $\mathrm{X}$-ray diffractometer (XRD) and a ball-on-disc microtribometer were used for the investigation of AISI D3 tool steels.

\section{Experimental details}

\subsection{Sample preparation}

Commercially available $12 \mathrm{~mm}$ diameter rods of AISI D3 raw materials were procured and confirmed by chemical analysis using optical emission spectrometer (GNR srl, Italy). The results are shown in Table 1. After confirming the materials procured for the test, the AISI D3 rods were machined into discs with $10 \mathrm{~mm}$ in diameter and $5 \mathrm{~mm}$ in thickness and segregated into three groups to study their mechanical and tribological properties. The as-received, conventionally heat treated without tempering and deep cryogenically treated without tempering samples were designated as RAW (Group 1), CHTWOT (Group 2) and DCTWOT (Group 3), respectively. The sample designations and heat treatment details are shown in Table 2. The CHTWOT samples were prepared by heating the Group 2 materials to $900{ }^{\circ} \mathrm{C}$ and soaked for $30 \mathrm{~min}$, which was followed by quenching in a room temperature oil (RT $\sim 30^{\circ} \mathrm{C}$ ). Similarly the Group 3 samples (DCTWOT) were prepared by heating the machined samples to $900{ }^{\circ} \mathrm{C}$ and soaked for $30 \mathrm{~min}$, which was followed by quenching in a RT oil $\left(30^{\circ} \mathrm{C}\right)$. After this process the Group 3 samples were immediately subjected to DCT cycle. During the DCT process the oil quenched samples were cooled from RT to $-196{ }^{\circ} \mathrm{C}$ in 6 hours followed by holding at $-196^{\circ} \mathrm{C}$ for 24 hours and finally heated back to RT in 6 hours. The DCT process was carried out using liquid nitrogen in A.C.I. CP-200vi cryogenic processor (Applied Cryogenics, Inc., Massachusetts, USA).

\subsection{Characterization}

The microstructure of the samples was characterized using a Philips MPD 1880 XRD with Cu-Ka radiation at $40 \mathrm{kV}$ and $30 \mathrm{~mA}$.

The surface roughness of the samples was measured using surface profilometry (Talyscan 150) with a diamond stylus of $4 \mu \mathrm{m}$ in diameter.

The surface morphology of the samples was examined using SEM (JEOL-JSM-5800) and OM (OM, Zeiss Axioskop 2, JVC color video camera).

For the microstructural observation, the samples were ground using 4,000 grit papers followed by polishing with diamond paste containing $1 \mu \mathrm{m}$ diamond particles on polishing cloths. Then, the mirror-like surfaces of the samples were etched with $4 \%$ nital and dried with compressed air.

Table 1 Chemical composition of AISI D3 steel.

\begin{tabular}{ccccccccccc}
\hline Element (wt\%) & $\mathrm{C}$ & $\mathrm{Si}$ & $\mathrm{Mn}$ & $\mathrm{P}$ & $\mathrm{S}$ & $\mathrm{Cr}$ & $\mathrm{V}$ & $\mathrm{W}$ & $\mathrm{Fe}$ \\
\hline AISI D3 & 2.09 & 0.645 & 0.23 & 0.018 & 0.017 & 12.72 & 0.05 & $<0.003$ & Balance \\
\hline
\end{tabular}

Table 2 Detailed treatments of AISI D3 steel.

\begin{tabular}{ccccc}
\hline Sample ID & Hardening temperature $\left({ }^{\circ} \mathrm{C}\right)$ & Soaking period $(\min )$ & Quench medium & DCT cycle \\
\hline RAW & NA & NA & NA & NA \\
CHTWOT & 900 & 30 & Oil at $30{ }^{\circ} \mathrm{C}$ & NA \\
DCTWOT & 900 & 30 & Oil at $30{ }^{\circ} \mathrm{C}$ & DCT Cycle \\
\hline
\end{tabular}

Note: NA - Not applicable, CHTWOT - Conventional heat treatment without tempering, DCTWOT - Deep cryogenic treatment without tempering 
The hardness of the samples was measured using a microindenter with a pyramidal shaped diamond tip. The indentation test was performed in a load control mode with a total load of about $10 \mathrm{~N}$. The average hardness of the samples was taken from four indentation measurements on each sample.

The tribological properties of the samples were investigated using a ball-on-disc micro-tribometer (CSM) by sliding them against alumina $\left(\mathrm{Al}_{2} \mathrm{O}_{3}\right)$ and $100 \mathrm{Cr} 6$ steel ball of $6 \mathrm{~mm}$ in diameter in a circular path of $2 \mathrm{~mm}$ in radius for about 25,000 laps at a sliding speed of $3 \mathrm{~cm} / \mathrm{s}$ under different normal loads at the lab temperature of about $22-24{ }^{\circ} \mathrm{C}$. The samples were polished using 1,200 grit papers prior to tribological test and their $R_{\mathrm{q}}$ values were about $0.51 \mu \mathrm{m}$. Three wear tests per sample were carried out to get an average friction coefficient. The average specific wear rate was calculated by measuring width and depth of wear tracks with surface profilometry.

\section{Results and discussion}

Figure 1 shows the microstructures of the AISI D3 samples with different treatments. In Figs. 1(a) and 1(b), the microstructure of the RAW exhibits non-uniform distribution of large, elongated white regions of primary chromium carbides and uniform distribution of smaller, nearly spherical secondary chromium carbides [20]. The conventional heat treatment of the AISI D3 sample promotes the uniform distribution of primary and secondary chromium carbides and reduces the size of the carbides, which is confirmed by the more homogenized carbide distribution and the reduced carbide size in the microstructure of the CHTWOT (Figs. 1(c) and 1(d)) compared to those in the original microstructure of the RAW (Figs. 1(a) and 1(b)). As shown in Figs. 1(e) and 1(f), the deep cryogenic treatment of the CHTWOT probably gives rise to the most homogenized carbide distribution and the smallest carbide size in the microstructure among the AISI D3 samples used in this study [5-16, 20].

Figure 2 illustrates the XRD patterns of the AISI D3 samples with different treatments. The untempered martensite peaks are visible in the XRD patterns of all the three samples although the relatively weak peaks that represent retained austenite are detected in the XRD patterns of the both RAW and CHTWOT.
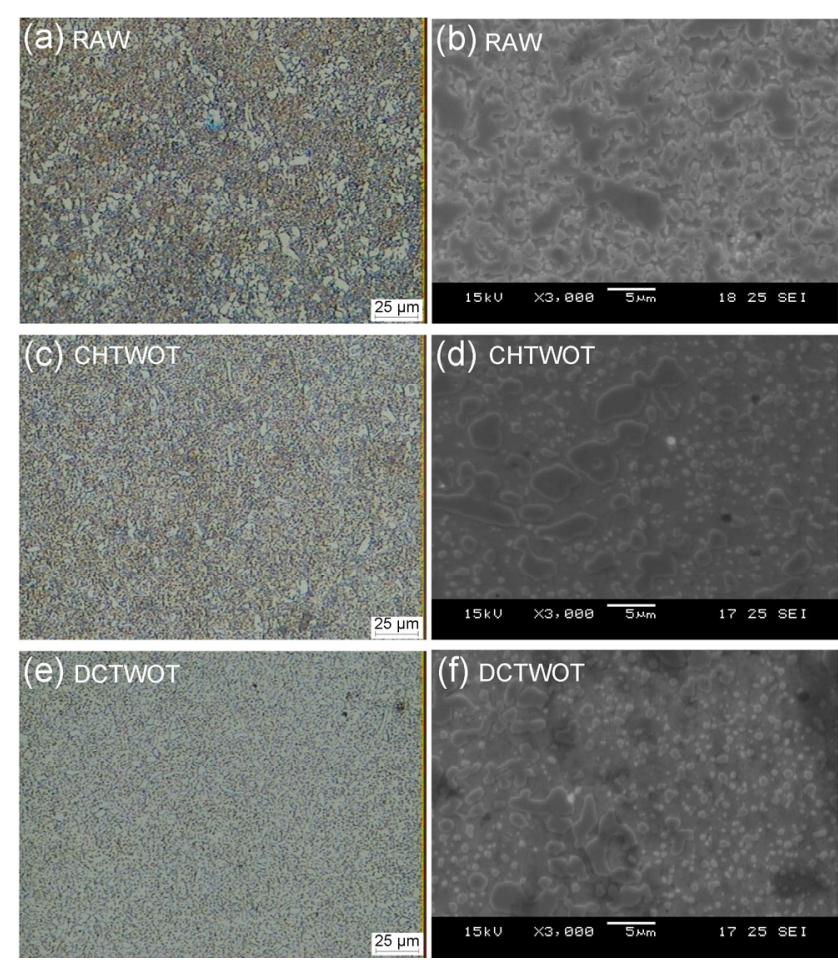

Fig. 1 Optical and SEM images showing microstructures of ((a) and (b)) RAW, ((c) and (d)) CHTWOT and ((e) and (f)) DCTWOT, respectively.

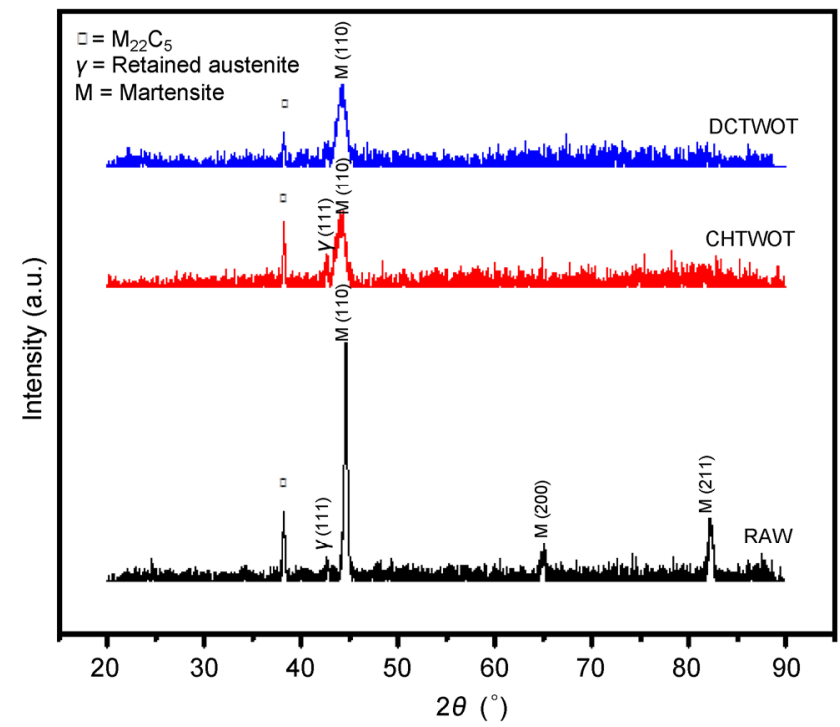

Fig. 2 XRD patterns of AISI D3 samples with different treatments.

Figure 3 shows the hardness values of the AISI D3 samples with different treatments measured with an applied load of about $10 \mathrm{~N}$. The RAW has a hardness of about $260 \mathrm{Hv}$. The CHTWOT has a hardness of about $962 \mathrm{Hv}$ which corresponds to chromium carbide $\left(\mathrm{Cr}_{23} \mathrm{C}_{6}\right)$ hardness along with untempered martensite 


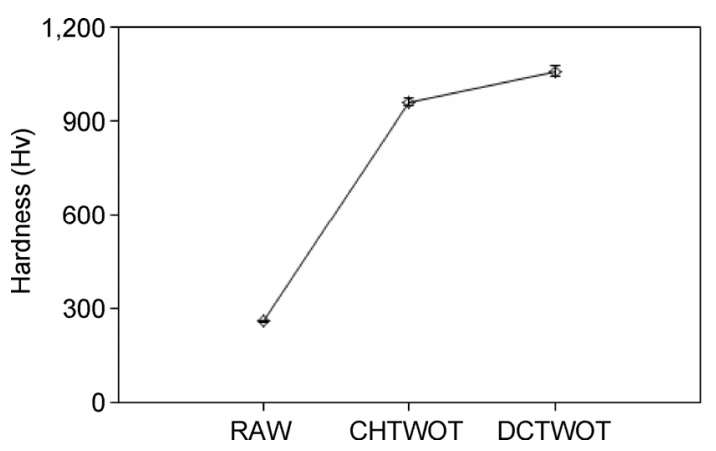

Fig. 3 Micro-hardness values of AISI D3 samples with different treatments.

and little amount of retained austenite. The DCTWOT has a hardness of about $1,059 \mathrm{Hv}$ which corresponds to chromium carbide hardness along with untempered martensite. The DCTWOT has the highest hardness among the AISI D3 samples used due to its most retained austenite elimination, most homogenized carbide distribution and most reduction in carbide size $[1,3,5-17,20]$.

Figure 4 presents the friction coefficients of the AISI D3 samples with different treatments tested against the alumina and 100Cr6 steel balls for about 25,000 laps at a sliding speed of $3 \mathrm{~cm} / \mathrm{s}$ under a normal load of $1 \mathrm{~N}$. The friction coefficients of the RAW, CHTWOT and DCTWOT tested against the alumina and steel balls are about 0.83 and 0.86 , about 0.81 and 0.82 and about 0.67 and 0.76 , respectively, which indicates that the CHTWOT has the lower friction than the RAW as the DCTWOT has the further lower friction. Normally, a large contact between two surfaces can give rise to a high friction via an effective interfacial shear strength between them [21]. Therefore, the opposite trends between the hardness (Fig. 3) and friction (Fig. 4) of the AISI D3 samples with different treatments suggest that the increased hardness of the treated AISI D3 samples is responsible for their decreased friction due to their reduced contact with the counter ball [21]. In addition, the untreated and treated AISI D3 samples exhibit the lower friction coefficients for the alumina ball than for the steel ball because of their smaller contact with the harder alumina ball during the sliding [21]. The inset in Fig. 4 shows the wear morphology of the alumina ball rubbed on the DCTWOT under the normal load of $1 \mathrm{~N}$ on which a relatively low wear is found.

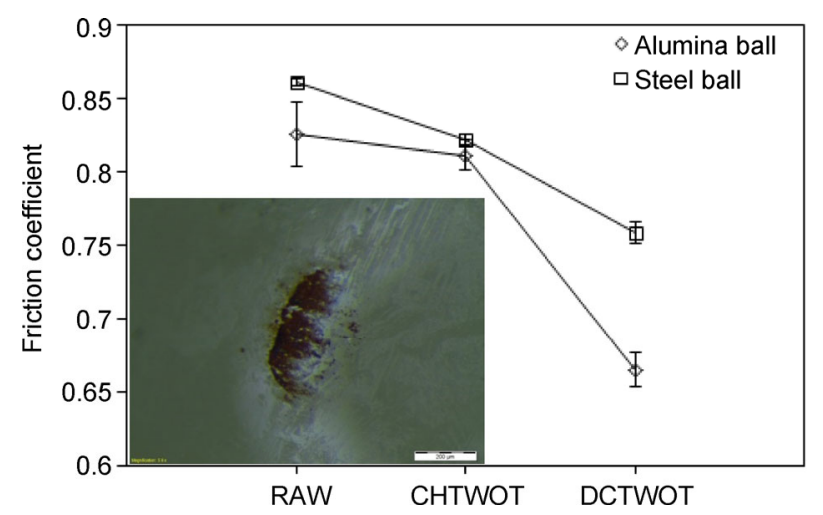

Fig. 4 Friction coefficients of AISI D3 samples with different treatments slid against alumina and 100Cr6 steel balls of $6 \mathrm{~mm}$ in diameter in a circular path of $2 \mathrm{~mm}$ in radius for about 25,000 laps at a sliding speed of $3 \mathrm{~cm} / \mathrm{s}$ under a normal load of $1 \mathrm{~N}$. The inset shows an optical image of a worn alumina ball rubbed on DCTWOT under the same condition as mentioned above.

Figure 5 illustrates the friction coefficients of the AISI D3 samples with different treatments tested against the alumina and steel balls under the normal load of $1 \mathrm{~N}$ as a function of the number of laps. In Fig. 5(a), the AISI D3 samples with different treatments exhibit a relatively stable friction during the entire sliding against the alumina ball due to their stable wear. However, the DCTWOT tested against the alumina ball exhibits a relatively much lower friction for the first 3,500 laps before reaching a stable friction for the rest, implying that the highest hardness of the DCTWOT effectively prevents an initiation of its surface wear. In addition, the CHTWOT and DCTWOT have the lower trends of friction coefficient versus laps than the RAW due to their smaller contact with the alumina ball associated with their higher hardness as the higher hardness of the DCTWOT compared to that of the CHTWOT gives rise to its lower trend of friction coefficient versus laps. Although the AISI D3 samples with different treatments tested against the steel ball exhibit the similar trends of friction coefficient versus laps as found in Fig. 5(b), their friction decreases with increased laps. Roughening of two rubbing surfaces can reduce the friction by lessening a real contact area between them $[22,23]$. In addition, the production of wear debris can also reduce the friction because the debris released to an interface between two rubbing surfaces can freely roll or slide under a lateral force [14-16, 24, 25]. Since oxidized wear debris are somewhat harder, the wear debris can help to reduce the friction 

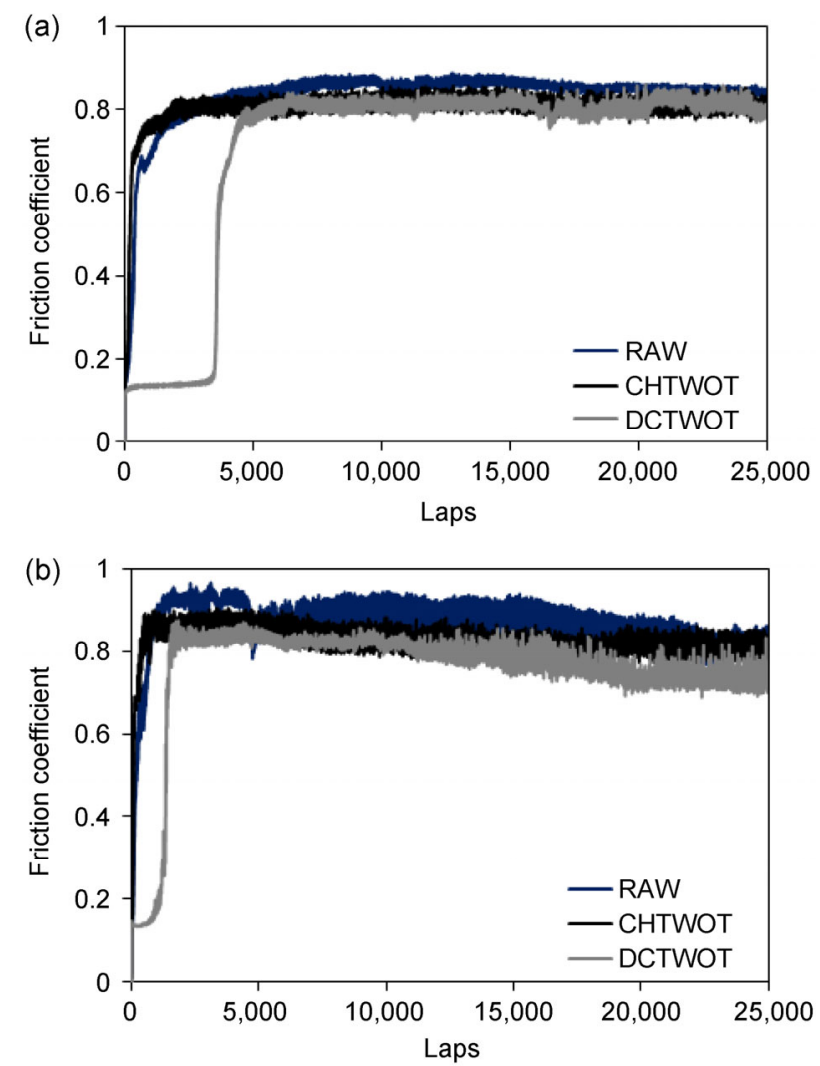

Fig. 5 Friction coefficients of AISI D3 samples with different treatments, slid against (a) alumina and (b) 100Cr6 steel balls of $6 \mathrm{~mm}$ in diameter under the same condition as described in Fig. 4, as a function of the number of laps.

by serving as spacers to prevent a direct contact between two rubbing surfaces [14-16, 24, 25]. Therefore, the promoted wear of the rubbing surfaces with prolonged sliding leads to the decreased friction of the AISI D3 samples with different treatments through the promoted surface roughening and production of wear debris (Fig. 5(b)) [22-24]. Such a decrease in the friction with prolonged sliding is found only for the AISI D3 samples tested against the steel ball probably due to the higher wear of the steel ball than that of the alumina ball during the sliding. The DCTWOT tested against the steel ball (Fig. 5(b)) exhibit a relatively low initial friction for the smaller number of laps compared to the one tested against the alumina ball (Fig. 5(a)) because the lower hardness of the steel ball than that of the alumina ball induces a larger contact between the steel ball and DCTWOT and gives rise to a higher interfacial shear strength between them, which in turn results in an earlier surface wear.

Figure 6 shows the specific wear rates of the AISI

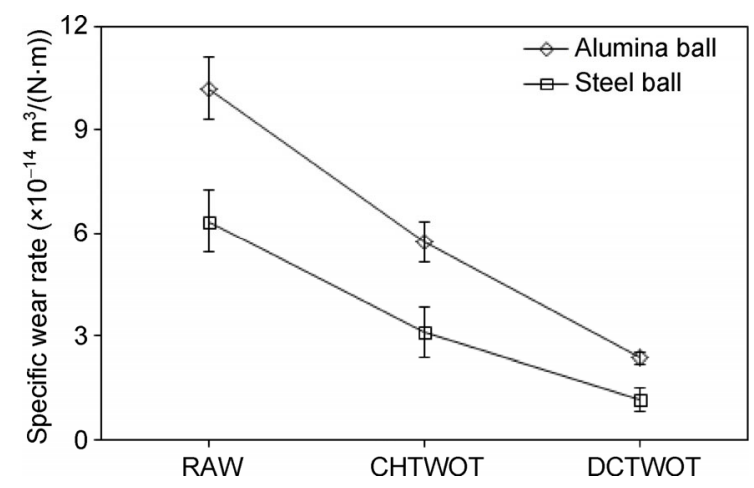

Fig. 6 Specific wear rates of AISI D3 samples with different treatments tested under the same conditions as described in Fig. 4.

D3 samples with different treatments tested against the alumina and steel balls for about 25,000 laps at a sliding speed of $3 \mathrm{~cm} / \mathrm{s}$ under a normal load of $1 \mathrm{~N}$. The specific wear rates of the RAW, CHTWOT and DCTWOT tested against the alumina and steel balls are about 10.2 and $6.3 \times 10^{-14} \mathrm{~m}^{3} /(\mathrm{N} \cdot \mathrm{m})$, about 5.7 and $3.1 \times$ $10^{-14} \mathrm{~m}^{3} /(\mathrm{N} \cdot \mathrm{m})$ and about 2.4 and $1.2 \times 10^{-14} \mathrm{~m}^{3} /(\mathrm{N} \cdot \mathrm{m})$, respectively. It indicates that the RAW and DCTWOT have the highest and lowest wear (Fig. 6) as a result of their lowest and highest hardnesses, respectively (Fig. 3). In addition, the similar trends between the friction (Fig. 4) and wear (Fig. 6) of the AISI D3 samples with different treatments indicate that the frictional behaviour of the AISI D3 samples is closely related to their wear behaviour. The AISI D3 samples tested against the alumina ball have the higher specific wear rates than the ones tested against the steel ball (Fig. 6) due to the higher hardness and wear resistance of the alumina ball than those of the steel ball. The results clearly show that the DCTWOT most effectively prevents its surface wear during the prolonged sliding against the both alumina and steel balls among the AISI D3 samples used due to its highest wear resistance attributed to its most retained austenite elimination, most homogenized carbide distribution and most reduction in carbide size $[1,3,17,20]$.

Figures 7(a)-7(c) show the wear morphologies of the AISI D3 samples with different treatments tested against the alumina ball. Abrasive lines are apparently found on their wear tracks, which indicates that the wear of the AISI D3 samples is mainly attributed to the abrasive wear caused by the repeated sliding of the alumina ball [24, 25]. However, the CHTWOT (Fig. 7(b)) exhibits the lower abrasive wear than the RAW 

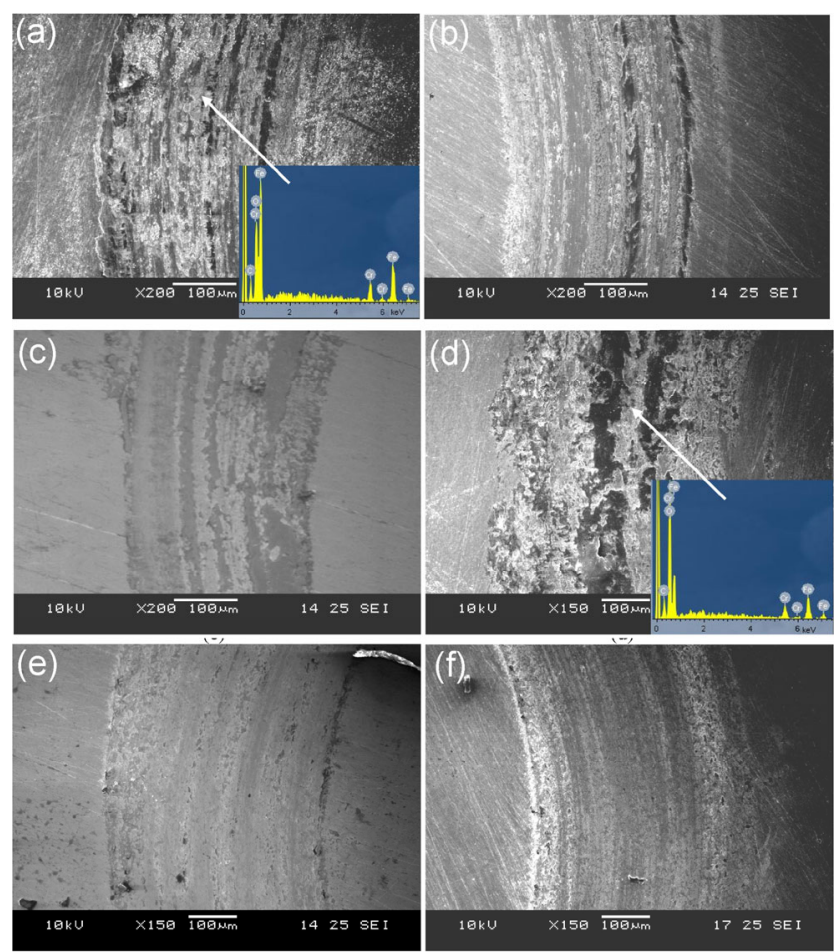

Fig. 7 SEM images showing surface morphologies of worn ((a) and (d)) RAW, ((b) and (e)) CHTWOT and ((c) and (f)) DCTWOT slid against ((a), (b) and (c)) alumina and ((d), (e) and (f) $100 \mathrm{Cr} 6$ steel balls of $6 \mathrm{~mm}$ in diameter under the same conditions as described in Fig. 4. The insets in (a) and (d) show EDX spectra of RAW slid against alumina and 100Cr6 steel balls, respectively, under the same conditions as described in Fig. 4.

(Fig. 7(a)), which indicates that the conventional heat treatment promotes the abrasive wear resistance of the RAW via its improved hardness. The DCTWOT exhibits the lowest abrasive wear among the AISI D3 samples tested against the alumina ball as a result of its highest abrasive wear resistance (Fig. 7(c)). The AISI D3 samples with different treatments tested against the steel ball exhibit the similar wear behaviour as found in Figs. 7(d)-7(f). Comparison of the wear morphologies of the AISI D3 samples tested against the alumina and steel balls shows that the repeated sliding of the alumina ball resutls in the more severe abrasive wear of the AISI D3 samples by removing surface materials from the deeper regions.

The wear tracks of the AISI D3 samples slid against the alumina and steel balls were examined using energy dispersive X-ray spectroscopy (EDX). The AISI D3 samples with different treatments exhibit the similar EDX spectra for the both alumina and steel balls. The insets in Figs. 7(a) and 7(d) show the EDX spectra of the RAW slid against the alumina and steel balls, respectively, on which the $\mathrm{C}, \mathrm{O}, \mathrm{Fe}$ and $\mathrm{Cr}$ peaks are detected. The $\mathrm{O}$ peaks on the both wear tracks are indicative of the oxidiation process caused by high fricitonal heat generated during the sliding [24, 25].

Figure 8(a) shows the friction coefficients of the AISI D3 samples with different treatments tested against the steel ball for about 25,000 laps under different normal loads. With increased normal load from 1 to $4 \mathrm{~N}$, the friction coefficients of the RAW, CHTWOT and DCTWOT significantly decrease from about 0.86 , 0.82 and 0.76 to about $0.8,0.74$ and 0.68 , respectively, because the increased wear of the rubbing surfaces associated with increased normal load reduces the interfacial shear strength between them by promoting the surface roughening and production of wear debris [21-24]. It is consistently found that the RAW and DCTWOT exhibit the highest and lowest friction coefficients for all the normal loads, respectively, which confirms that the highest hardness of the DCTWOT is responsible for its lowest friction due to its smallest contact with the steel ball.
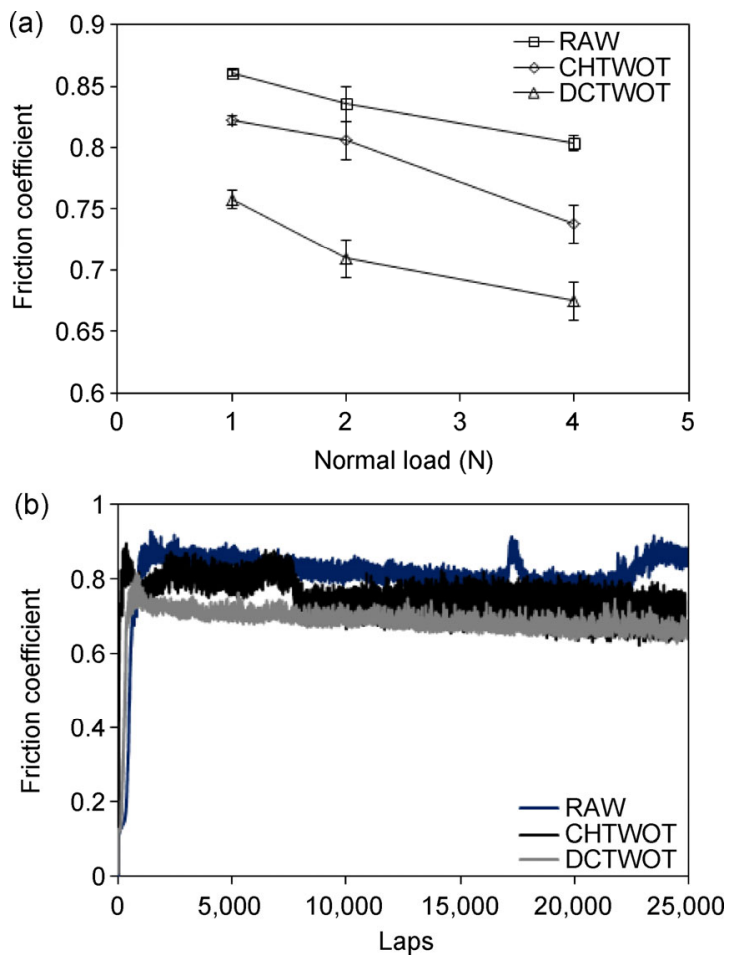

Fig. 8 Friction coefficients of AISI D3 samples with different treatments slid against a 100Cr6 steel ball of $6 \mathrm{~mm}$ in diameter in a circular path of $2 \mathrm{~mm}$ in radius for about 25,000 laps at a sliding speed of $3 \mathrm{~cm} / \mathrm{s}$ as functions of (a) normal load and (b) the number of laps under $4 \mathrm{~N}$ normal load. 
Figure 8(b) illustrates the friction coefficients of the AISI D3 samples with different treatments tested against the steel ball under the normal load of $4 \mathrm{~N}$ as a function of the number of laps. The friction of the RAW decreases with increased laps till there is a slight increase in the friction caused by the higher surface wear. However, such an increase in the friction is not found for the CHTWOT and DCTWOT, implying that the improved hardness of the CHTWOT and DCTWOT results in the more stable wear throughout the wear test. A decrease in the friction with increased laps is found for all the samples due to the promoted surface roughening and production of wear debris during the prolonged sliding $[22,23]$. In Fig. 8(b), the DCTWOT tested against the steel ball under the normal load of $4 \mathrm{~N}$ does not exhibit the relatively low initial friction that is apparently found in Figs. 5(a) and 5 (b) because the normal load of $4 \mathrm{~N}$ is high enough to immediately initiate the wear of the rubbing surfaces, which is confirmed by the decreased number of laps required to reach the relatively high friction of the DCTWOT tested against the steel ball with increased normal load (Figs. 5(b) and 8(b)). It is clearly found in Figs. 5(a), 5(b) and 8(b) that the AISI D3 samples with different treatments exhibit a stable friction during the entire sliding against the alumina ball under $1 \mathrm{~N}$ as a result of their stable wear, but a decrease in the friction during the prolonged sliding against the steel ball under all the normal loads via the promoted surface roughening and production of wear debris.

Figure 9 presents the specific wear rates of the AISI D3 samples with different treatments slid against the steel ball at a sliding speed of $3 \mathrm{~cm} / \mathrm{s}$ under different normal loads. Increasing the normal load from 1 to $4 \mathrm{~N}$ increases the specific wear rates from about 6.3 to $9.5 \times 10^{-14} \mathrm{~m}^{3} /(\mathrm{N} \cdot \mathrm{m})$ for the RAW, from about 3.1 to $5.3 \times$ $10^{-14} \mathrm{~m}^{3} /(\mathrm{N} \cdot \mathrm{m})$ for the CHTWOT and from about 1.2 to $3.3 \times 10^{-14} \mathrm{~m}^{3} /(\mathrm{N} \cdot \mathrm{m})$ for the DCTWOT, respectively. It can be seen that the RAW and DCTWOT exhibit the highest and lowest wear, respectively, for all the normal loads as the wear of the AISI D3 samples with different treatments significantly increases with increased normal load. It is clear that the deep cryogenic treatment significantly improves the wear resistance of the CHTWOT due to the more retained austenite elimination, more homogenized carbide distribution and more reduction in carbide size in the microstructure [1, 3-17, 20].

Figures 10(a)-10(c) show the worn surfaces of the AISI D3 samples with different treatments slid against the steel ball under the normal load of $4 \mathrm{~N}$, from which the RAW exhibits the most severe wear (Fig. 10(a)). Comparison of Fig. 7(d) and Fig. 10(a) clearly shows the promoted wear of the RAW with increased normal load. During the sliding, the wear of the rubbing surfaces produces wear debris and the repeated sliding of the steel ball compacts the debris to form a tribolayer on the wear track [24-27]. Therefore, the tribolayers are apparently found on the wear tracks of the RAW slid against the steel ball under the normal loads of 1 and $4 \mathrm{~N}$ (Figs. 7(d) and 10(a)). However, the RAW slid against the alumina ball under the normal load

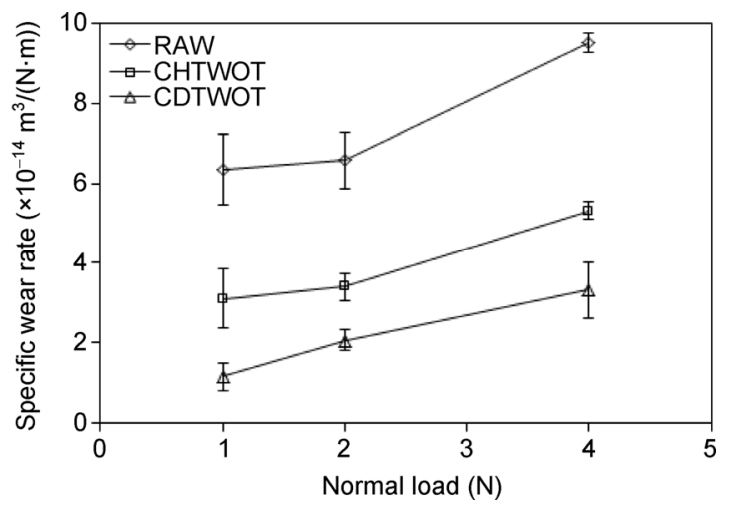

Fig. 9 Specific wear rates of AISI D3 samples with different treatments tested under the same conditions as described in Fig. 8.
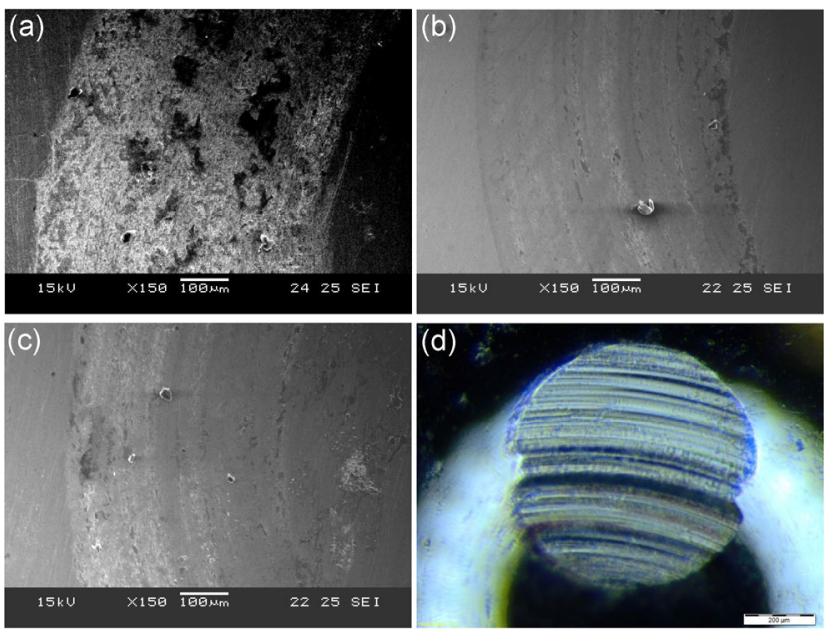

Fig. 10 SEM images showing surface morphologies of worn (a) RAW, (b) CHTWOT and (c) DCTWOT slid against a 100Cr6 steel ball of $6 \mathrm{~mm}$ in diameter in a circular path of $2 \mathrm{~mm}$ in radius for about 25,000 laps at a sliding speed of $3 \mathrm{~cm} / \mathrm{s}$ under a normal load of $4 \mathrm{~N}$ and (d) an optical image of a worn steel ball rubbed on DCTWOT under the same conditions as mentioned above. 
of $1 \mathrm{~N}$ (Fig. 7(a)) exhibits the less formation of the tribolayers on the wear track than the one tested against the steel ball under the same normal load (Fig. 7(d)), which implies that the higher wear of the steel ball than that of the alumina ball contributes to the formation of the tribolayers on the wear track. As shown in Fig. 10(b), the CHTWOT has the lower wear than the RAW because the conventional heat treatment of the RAW apparently improves the wear resistance by promoting the hardness of the RAW (Fig. 3). The deep cryogenic treatment of the CHTWOT further lowers the wear (Fig. 10(c)) via the further improved hardness of the CHTWOT (Fig. 3). As a result, the improved wear resistance of the CHTWOT and DCTWOT significantly lessens the formation of the tribolayers on their wear tracks (Figs. 10(b) and 10(c)).

Figure 10(d) shows the worn surface of the steel ball slid on the DCTWOT under the normal load of $4 \mathrm{~N}$ on which a significant wear is found. In addition, the worn surface of the steel ball has a wear pattern with significant abrasive lines. It is clear that the sliding of the steel ball on the AISI D3 samples gives rise to a significant wear of the steel ball, which confirms that the promoted wear of the steel ball is also responsible for the decreased friction during the prolonged sliding by promoting the surface roughening of the steel ball and the production of wear debris (Figs. $5(b)$ and $8(b)$ ).

\section{Conclusions}

The effects of DCT on the mechanical and tribological properties of AISI D3 tool steel samples were systematically investigated. The DCTWOT was much harder than the RAW and CHTWOT because the DCTWOT had the more retained austenite elimination, more homogenized carbide distribution and more reduction in carbide size in the microstructure compared to the RAW and CHTWOT. The tribological results showed that the friction and wear of the DCTWOT slid against the alumina and 100Cr6 steel balls were significantly lower than those of the RAW and CHTWOT due to the higher wear resistance of the DCTWOT. The decreased friction and increased wear of the AISI D3 tool steel samples slid against the steel ball with increased normal load from 1 to $4 \mathrm{~N}$ revealed that the increased wear of the AISI D3 tool steel samples was responsible for their decreased friction due to the promoted surface roughening and production of wear debris. However, the DCTWOT slid against the steel ball exhibited the lower friction and wear for all the normal loads than the RAW and CHTWOT. It could be concluded that the DCT was a promising supplemental treatment to improve the hardness and wear resistance of the conventionally heat treated AISI D3 tool steel.

Open Access: This article is distributed under the terms of the Creative Commons Attribution License which permits any use, distribution, and reproduction in any medium, provided the original author(s) and source are credited.

\section{References}

[1] Saha S K, Prasad L, Kuma V. Experimental investigations on heat treatment of cold work tool steels: Part 1, air hardening grade (D2). Int J Eng Res Appl 2(2): 510-519 (2012)

[2] Podgornika B, Majdicb F, Leskovseka V, Vizintinb J. Improving tribological properties of tool steels through combination of deep cryogenic treatment and plasma nitriding. Wear 288: 88-93 (2012)

[3] Bensely A, Prabhakaran A, Lal D M, Nagarajan G. Enhancing the wear resistance of case carburized steel (En 353) by cryogenic treatment. Cryogenics 45: 747-754 (2006)

[4] Akhbarizadeh A, Shafyei A, M. A. Golozar M A. Effects of cryogenic treatment on wear behaviour of D6 tool steel. Mater Design 30: 3259-3264 (2009)

[5] Grill S S, Singh J, Sigh R, Sigh H, Metallurgical principals of cryogenically treated tool steels-A review on the current state of science. Int J Adv Manfu Technol 54: 59-82 (2011)

[6] Cohen P, Kamody D. Cryogenics goes deeper. Cutt Tool Eng 150(7): 46-50 (1998)

[7] Barron R F. Cryogenic treatments on metals to improve wear resistance. Cryogenics 22: 409-414 (1982)

[8] Yang H S, Wang J, Shen B L, Liu H H, Gao S J, Huang S J. Effect of cryogenic treatment on the matrix structure and abrasion resistance of white cast iron subjected to destabilization treatment. Wear 26: 1150-1154 (2006)

[9] Preciado M, Bravo P M, Alegre J M. Effect of low temperature tempering prior cryogenic treatment on carburized steel. J Mater Process Technol 176(1-3): 41-44 (2006)

[10] Collins D N. Deep cryogenic treatment of tool steels-A review. Heat Treat Met 23(2): 40-42 (1996) 
[11] Collins D N, Dormer J. Deep cryogenic treatment of a D2 cold worked tool steel. Heat Treat Met 3: 71-74 (1997)

[12] Mohan Lad D, Renganarayanan S, Kalanidhi A. Cryogenic treatment to augment wear resistance of tool and die steels. Cryogenics 41(3): 149-155 (2001)

[13] Leskovsek V, Kalin M, Vizintin J. Influence of deep cryogenic treatment on wear resistance of vacuum heat treated HSS. Vacuum 80: 507-518 (2006)

[14] Das D, Dutta A K, Ray K K. Correlation of microstructure with wear behaviour of deep cryogenically treated AISI D2 tool steel. Wear 267: 1371-1380 (2009)

[15] Kalin M, Leskovsek V, Vizintin J. Wear behaviour of deep cryogenic treated high speed steel at different loads. Mater Manuf Process 21: 741-746 (2006)

[16] Firouzdor V, Nejati E, Khomamizaheh F. Effect of deep cryogenic treatment on wear resistance and tool life of M2 HSS drill. J Mater Process Technol 206: 467-472 (2008)

[17] Dixit S S, Nimbalkar S R, Kharde R R. Dry sliding wear analysis of D5 tool steel at different heat treatments. Int J Eng Sci 2(5): 16-26 (2013)

[18] Dhokey N B, Nirbhavane S. Dry sliding wear of cryo-treated multiple tempered D3 tool steel. J Mater Process Technol 209(3): 1484-1490 (2009)

[19] Molinari A, Pellizzari M, Gialanella S, Straffelini S, Stiasny $\mathrm{K} \mathrm{H}$. Effect of deep cryogenic treatment on the mechanical

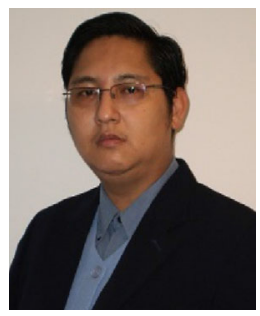

Nay Win KHUN. He received his MSc degree in "mechanics and processing of materials" in 2006 and his PhD degree in "physics and electrochemistry of thin films" in

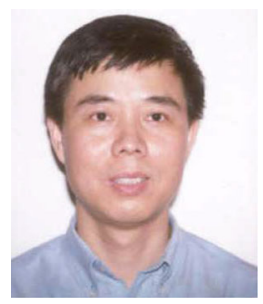

Erjia LIU. He received his $\mathrm{PhD}$ degree in metallurgy and materials engineering from K.U. Leuven, Belgium. He is currently an associate professor with the School of properties of tool steels. J Mater Process Technol 118: 350-355 (2001)

[20] Naravade R H, Belkar S B, Kharde R R. Effects of cryogenic treatment, hardening and multiple tempering on wear behaviour of D6 tool steel. Int J Eng Sci 2(5): 1-15 (2013)

[21] Blau P J. Friction Science and Technology. New York: Marcel Dekker, 1996.

[22] Qu J, Blau P J, Watkins T R, Cavin O B, Kulkarni N S. Friction and wear of titanium alloys sliding against metal, polymer and ceramic counterfaces. Wear 258: 1348-1356 (2005)

[23] Bhushan B. Tribology and Mechanics of Magnetic Storage Device. $2^{\text {nd }}$ edition. New York: Springer-Verleg, 1996.

[24] Khun N W, Li R T, Loke K, Khor K A. Effects of Al-Cr-Fe quasicrystal content on tribological properties of cold sprayed titanium composite coatings. Tribol Trans 58: 616-624 (2015)

[25] Li R T, Dong Z L, Khun N W, Khor K A. Novel Ti based metal matrix composites reinforced with $\mathrm{Al}-\mathrm{Cr}-\mathrm{Fe}$ quasicrystals approximants. Mater Sci Technol 31(6): 688-694 (2015)

[26] Meng J, Loh N H, Tay B Y, Fu G, Torr S B. Tribological behaviour of $316 \mathrm{~L}$ stainless steel fabricated by micro powder injection molding. Wear 268: 1013-1019 (2010)

[27] Khun N W, Frankel G S. Effects of normal load. sliding speed and surface roughness on tribological properties of niobium under dry and wet conditions. Tribo Trans 57: 944-954 (2014)

2011, both from the Nanyang Technological University, Singapore. His research interests include composite materials, thin films, coatings, tribology, corrosion, surface, and interface.

Mechanical and Aerospace Engineering, Nanyang Technological University, Singapore. His research interests include thin films, coatings, carbon materials, nanocomposites, nanotribology, nanomechanics, and electrochemistry. 